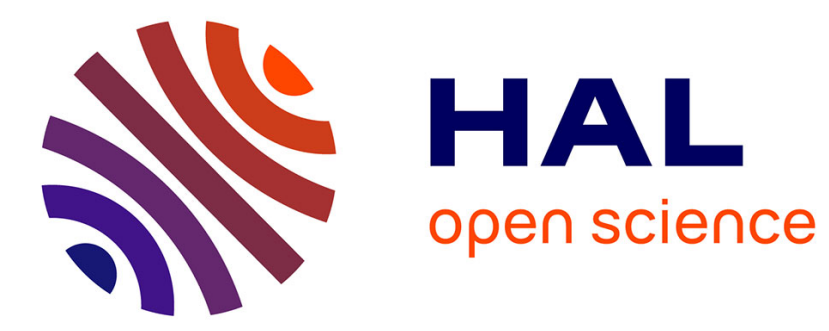

\title{
Influence of Water Content on the Mechanical Behaviour of Limestone: Role of the Clay Minerals Content
}

Fabien Cherblanc, Jérémie Berthonneau, Philippe Bromblet, Vincent Huon

\section{To cite this version:}

Fabien Cherblanc, Jérémie Berthonneau, Philippe Bromblet, Vincent Huon. Influence of Water Content on the Mechanical Behaviour of Limestone: Role of the Clay Minerals Content. Rock Mechanics and Rock Engineering, 2016, 49 (6), pp.2033-2042. 10.1007/s00603-015-0911-y . hal-01256315

\section{HAL Id: hal-01256315 \\ https://hal.science/hal-01256315}

Submitted on 14 Jan 2016

HAL is a multi-disciplinary open access archive for the deposit and dissemination of scientific research documents, whether they are published or not. The documents may come from teaching and research institutions in France or abroad, or from public or private research centers.
L'archive ouverte pluridisciplinaire HAL, est destinée au dépôt et à la diffusion de documents scientifiques de niveau recherche, publiés ou non, émanant des établissements d'enseignement et de recherche français ou étrangers, des laboratoires publics ou privés. 


\title{
Influence of water content on the mechanical behaviour of limestone: Role of the clay minerals content
}

\author{
F. Cherblanc ${ }^{1}$, J. Berthonneau ${ }^{2}$, P. Bromblet ${ }^{2}$, and V. Huon ${ }^{1}$ \\ ${ }^{1}$ Laboratoire de Mécanique et Génie Civil, CNRS, Université de Montpellier, Place \\ Eugène Bataillon, 34000 Montpellier, France \\ ${ }^{2}$ Centre Interdisciplinaire de Conservation et de Restauration du Patrimoine, 21 rue \\ Guibal, 13003 Marseille, France
}

January 11, 2016

\begin{abstract}
The mechanical characteristics of various sedimentary stones significantly depend on the water content, where $70 \%$ loss of their mechanical strengths can be observed when saturated by water. Furthermore, the clay fraction has been shown to be a key factor of their hydro-mechanical behaviour since it governs for instance the hydric dilation. This work aims at investigating the correlations between the clay minerals content and the mechanical weakening experienced by limestones when interacting with water. The experimental characterization focuses on five different limestones that exhibit very different micro-structures. For each of them, we present the determination of clay minerals composition, the sorption isotherm curve and the dependences of tensile and compressive strengths on the water content. It emerges from these results that, first, the sorption behaviour is mainly governed by the amount of smectite layers which exhibit the larger specific area and, second, the rate of mechanical strength loss depends linearly on the sorption capacity. Indeed, the clay fraction plays the role of a retardation factor that delays the appearance of capillary bridges as well as the mechanical weakening of stones. However, no correlation was evidenced between the clay content and the amplitude of weakening. Since the mechanisms whereby the strength decreases with water content are not clearly established, these results would help to discriminate between various hypothesis proposed in the literature.
\end{abstract}

\section{Introduction}

Arising from atmospheric humidity or ground capillary uptake, natural stones never evolve in dry conditions but undergo cyclic water content variations. As a porous medium, their mechanical behaviour generally depend on their hydric state and makes it essential to carry 
out the experimental characterization in a hydro-mechanical framework. This issue is of first importance in civil engineering since it is a common material in historic constructions. For instance, the building stones used in cultural heritage undergo various weathering processes associated with water transport inside their micro-structure (Benavente et al, 2008). A particular stone deterioration pattern is called "spalling" or "contour scaling" (Vergès-Belmin, 2008), it corresponds to the progressive loss of plates from surfaces exposed to rain and/or runoff whatever their position in the building. The plane of detachment is located near the stone surface and develops perpendicularly to the bedding so that it cannot result from mechanical weaknesses linked to the sedimentary origin of limestones (Berthonneau et al, 2014, 2015).

The dependences of mechanical properties on the moisture content have been thoroughly characterized for various types or rocks (sandstones, limestones, chalk, gypsum, ...) (Hawkins and McConnell, 1992; West, 1994; Grgic et al, 2005; Vásárhelyi and Ván, 2006; Talesnick and Shehadeh, 2007; Erguler and Ulusay, 2009; Yilmaz, 2010). When plotting the variation of tensile or compressive mechanical strength as a function of the water content, it exhibits a sharp decrease for low water content and remains almost constant for larger water content. The saturated ultimate strengths can be up to $70 \%$ lower than the dry one. Many works have focused on the softening/weakening coefficient with the objective to highlight some correlation with various petrophysical characteristics such as the porosity (Morales-Demarco et al, 2007; Vasconcelos et al, 2008; Török and Vásárhelyi, 2010), the density (Vásárhelyi, 2005; MoralesDemarco et al, 2007; Török and Vásárhelyi, 2010) or the mineral composition (Yilmaz et al, 2011). To date, the mechanisms that govern this weakening behaviour have not been clearly identified. Various hypotheses have been put forward while none of them have unanimous support. The most classical approaches rely on suction decrease, frictional reduction and fracture energy reduction

Clay minerals are common components of the clastic fraction of sedimentary stones. Even with a small content, the clayey phase makes them highly susceptible to water content variation and may govern the hydro-mechanical behaviour. For instance, hydric dilation behaviour is directly related to the amount of swelling clay of various natural stones (Colas et al, 2011; Berthonneau et al, 2015). Under cyclic conditions of wetting and drying, swelling and shrinkage phenomena can have a major role in the deterioration processes (Jiménez-González et al, 2008; Ruedrich et al, 2011; Berthonneau et al, 2014). Numerous studies on stone conservation point out the swelling clay content to be a key factor in durability evaluation of sedimentary stones (Weiss et al, 2004; Franzini et al, 2007; Sebastián et al, 2008; Berthonneau et al, 2014). While this phenomenological scenario accounting for stone damage seems to be well accepted, the underlying physical phenomena have not been clearly characterized. In particular, since the clay content plays a major role in the hydro-mechanical behaviour of limestones, it should certainly influence the weakening process.

Based on these considerations, this paper explores the implication of the swelling clay frac- 
tion with regard to the mechanical weakening due to moisture uptake. Five limestones used in current and historical buildings are under investigation. They are characterized by very different swelling clay contents to cover a wide range of stone type. The precise quantification of clay composition takes advantage of a new methodology developed recently coupling transmission electron microscopy, energy dispersive spectrometry, X-ray diffraction and numerical modelling. Then, adsorption isotherm curve is measured for each sample. Indeed, it is known to be a relevant indicator of the clay content and represents an essential characteristic of the hydro-mechanical behaviour. Eventually, tensile and compressive mechanical strengths of the five limestones are determined over the full range of water content, from dryness to water saturation. Correlating the different results underlines the role of clay minerals in the weakening phenomenon. This would help discriminating between the several physical hypothesis put forth to describe the hydro-mechanical coupling.

\section{Materials}

In this work, five different types of limestone are under investigation (ES: Estaillades, BM: Modern Barutel, BA: Antique Barutel, CY: Yellow Caromb, CG: Grey Caromb). The Barutel limestone was used by Romans for building purposes. It has been extracted at few kilometres in the north of the town of Nîmes (30 - France). The antique Barutel stone samples come from the masonry of the amphitheatre of Nîmes while the modern one was taken from the active quarry used for restoration located few hundred of meters far from the antique quarry. Barutel stone is a fine grained yellowish to greyish limestone of Barremian age (129 -125 Ma). It is a bioclastic mudstone (Dunham classification) with small marine bioclasts, mainly forams and quartz $(<100 \mu m)$, embedded in a fine calcitic matrix (Figs. 1a and 1b).

Caromb and Estaillades stones belong to the "Pierre du Midi" type, a Burdigalian (20-16 Ma) deposit extensively used for building in the Provence region since antiquity. Two kinds of Caromb stone were used for building, the yellow (CY) and the grey (CG) ones. Materials were sampled from the ancient quarry and a deposit of ancient stones coming from dismantling of old buildings in the village of Caromb (84 - France). The Estaillades limestone was collected from the active quarry near the village of Oppèdes ( 84 - France) in the same geographical area. Caromb and Estaillades limestones are bioclastic packstones (Dunham). Their textures were mainly composed by bioclastic fragments (Red Algae, Bryozoans, Bivalvia, Echinoderms, Forams, and lithoclasts) and two groups were distinguished. Large fragments $(>500 \mu m)$ cemented by a sparse and unevenly distributed calcareous matrix were observed in CY and ES (Figs. 1c and 1e). Fragments of smaller dimensions $(<200 \mu m)$ dispersed in a greyish marl matrix were recognized in $\mathrm{CG}$ together with ferruginous coatings and glauconite grains (Fig. 1d). Angular quartz grains $(\approx 200 \mu \mathrm{m})$ as well as greenish glauconitic fillings of bioclasts (mainly Bryozoans) were present in all samples except in ES.

Main petrophysical properties (density, effective porosity, Hirschwald coefficient and capil- 

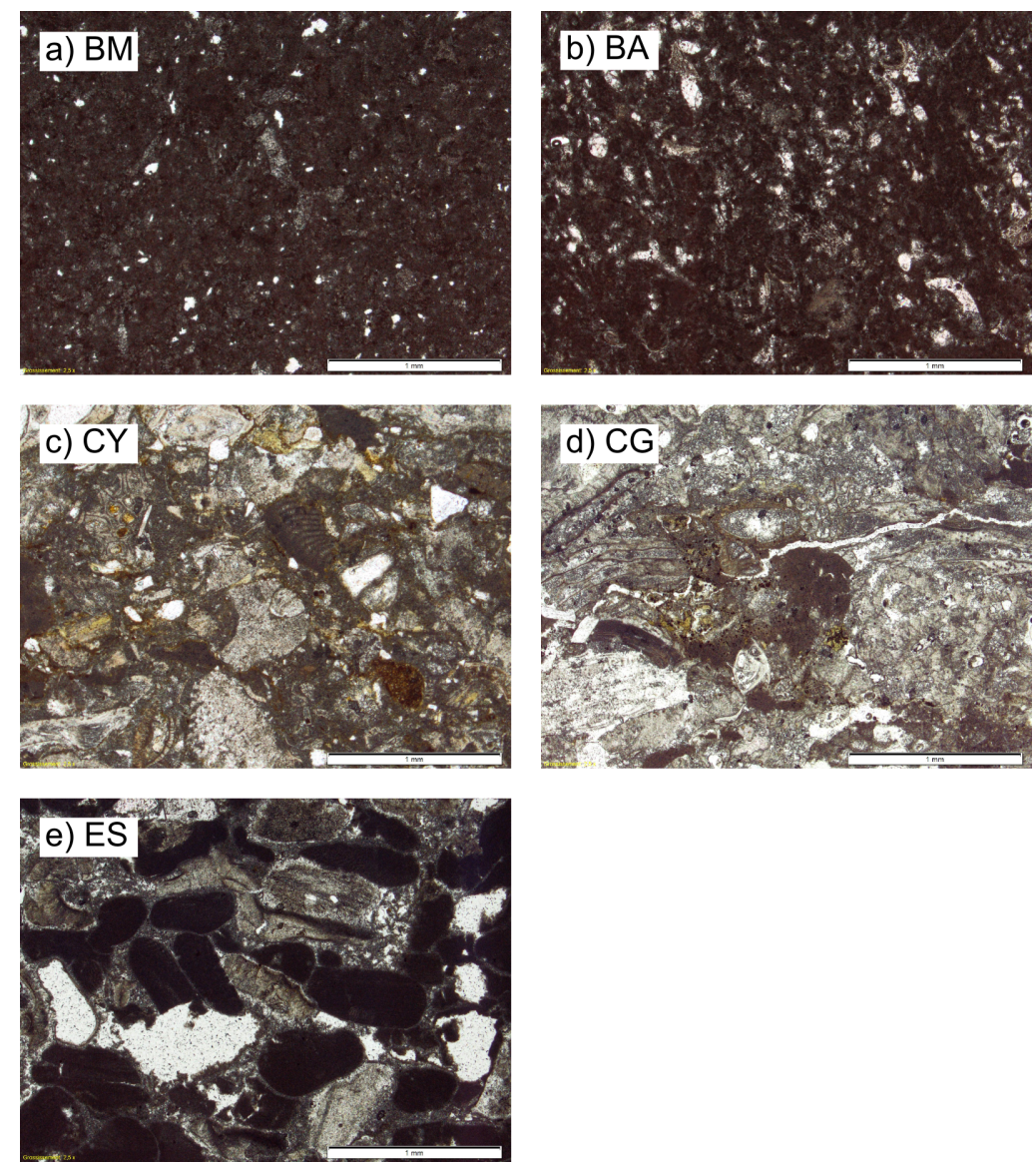

Figure 1: Microphotographs of samples BM, BA, CY, CG and ES acquired in polarized light microscopy.

larity) of each sample were measured on six cores $(h=80 \mathrm{~mm}, d=40 \mathrm{~mm})$ drilled perpendicularly to the bedding plane according to the French and European standards (NF B10-503, EN 13755 and NF B10-502). These characteristics are summarized in Tab. 1 highlighting the wide variety of samples under investigation. Antique and modern Barutel stones show uniform pore size distributions while Estaillades stone exhibits a perfect bimodal pore size distribution (Berthonneau et al, 2015).

\section{Experimental characterization}

\subsection{Mineralogical composition}

Mineralogical characterization was conducted by calcimetry (NF X 31-105) and X-ray diffraction (XRD) on total and acid (acetic acid $0.2 \mathrm{~N}$ ) insoluble powders. Diffractograms were recorded on a Bruker D8 Focus diffractometer (CoK $\alpha$ radiation) equipped with a Lynx'Eye detector operating with an aperture of $1^{\circ} 2 \theta$. 
Table 1: Main petrophysical properties of samples measured perpendicularly to the bedding plane

\begin{tabular}{rccccc}
\hline & ES & BM & BA & CY & CG \\
\hline Density $\left[\mathrm{kg} \cdot \mathrm{m}^{-3}\right]$ & $1884 \pm 32$ & $2272 \pm 15$ & $2182 \pm 19$ & $2097 \pm 27$ & $2111 \pm 23$ \\
Effective porosity $N[\%]$ & 31.7 & 16.1 & 19.7 & 22.3 & 20.7 \\
Hirschwald coefficient $S[\%]$ & 79 & 90 & 90 & 68 & 72 \\
Absorption coefficient $A\left[\mathrm{~g} \cdot \mathrm{cm}^{-2} \cdot \mathrm{h}^{-1 / 2}\right]$ & 1.8 & 0.18 & 0.40 & 0.18 & 0.19 \\
Capillary fringe speed $B\left[\mathrm{~cm} \cdot \mathrm{h}^{-1 / 2}\right]$ & 7.4 & 1.4 & 2.5 & 1.3 & 1.4 \\
\hline
\end{tabular}

Clay mineral identification and quantification were done on the clay fraction $(<4 \mu \mathrm{m})$ through the combination of transmission electron microscopy (TEM, JEOL JEM 2011) coupled with an energy-dispersive X-ray spectrometer (EDX, X-Flash Silicon Drift Detector 5030, Bruker) and profile modelling of XRD patterns of oriented preparations. Details on the elemental quantification and structural formula calculation from TEM microanalysis can be found in Berthonneau et al (2014). XRD patterns were collected on oriented preparations saturated with calcium $(\mathrm{Ca})$ at $0.01426^{\circ} 2 \theta$ step intervals from 2.5 to $60^{\circ} 2 \theta$, using a 4 seconds counting time per step. A first set of XRD patterns was acquired after drying at room temperature $(\mathrm{Ca}+\mathrm{AD})$, then the same preparations were exposed to ethylene glycol $(\mathrm{Ca}+$ EG) vapour for at least 24 hours and re-analysed. All the experimental XRD patterns were fitted over the $4.5-60^{\circ} 2 \theta$ CoK $\alpha$ range using the ASN program (Drits and Tchoubar, 1990; Lanson et al, 2009; Ferrage et al, 2011).

Eventually, the quality of the simulation was estimated using the unweighted goodness of fit parameter Rp (Howard and Preston, 1989). This parameter was calculated over the $5-60^{\circ} 2 \theta$ range, excluding the hkl reflections, and was used as an estimation of the error associated to the final quantitative values.

The quality of the fits was mainly influenced by the low crystallinity of the phyllosilicates structures and the presence of strong hkl reflections of quartz. These mismatches explained the relatively high values of the goodness of the fit parameters $(\mathrm{Rp})$, especially for the Barutel stones (BA, BM). In order to account for it within the proposed quantitative models, the evolution of the diffracted intensity of the 101 reflections of quartz was studied as a function of its weight fraction in a mixture with pure Na-Montmorillonite (Swy-2). The results showed a linear trend which slope was used to provide a precise estimation of the quartz content of the analysed clay fractions. These results varied from 0.21 (CY) to 6.02 wt.\% (BA) with an error of about $5 \%$.

The total contents of each clay mineral are given in Tab 2. Estaillades limestone is a pure calcite rock while the clay content varied from $1.7 \%$ to $2.6 \%$ in Caromb stones. One can note the significant amount of quartz in the clay fraction of Barutel stones. Since the smectite 
Table 2: Results of the clay mineral layers quantification given in percentage of the total mass. Smectite kind are written italicized

\begin{tabular}{rccccc}
\hline Clay type & ES & BM & BA & CY & CG \\
\hline Beidellite & 0 & 0.024 & 0.049 & & \\
Montmorillonite & 0 & 0.016 & 0.0046 & 0.390 & 0.700 \\
Muscovite & 0 & & & 0.780 & 0.570 \\
Glauconite & 0 & & & 0.523 & 1.21 \\
Illite & 0 & 0.285 & 0.159 & & \\
Kaolinite & 0 & 0.146 & 0.167 & & \\
Chlorite & 0 & & & & 0.103 \\
Quartz & 0 & 4.73 & 6.02 & 0.210 & 0.22 \\
\hline
\end{tabular}

group (Beidellite and Montmorillonite) presents the larger specific area (Woodruff and Revil, 2011; Revil and Lu, 2013), it will have the more significant impact on the sorption behaviour. In the following, we will therefore focus only on the smectite layers.

\subsection{Sorption isotherm}

Vapour sorption behaviour have been characterized using 9 standard saturated salt solutions to cover the whole range of $R H$, from $12 \%$ to $97 \%$. It has been done along the adsorption path starting from dry samples. Measurements were carried out on cylindrical slices $(40 \mathrm{~mm}$ diameter $\times 15 \mathrm{~mm}$ thick) and repeated using between 3 to 5 samples for each imposed $R H$. The number of samples was increased to 10 for high humidity $(R H=75,85$ and $97 \%)$ since the scattering of measures is generally larger when capillary bridges appear.

From the experimental points, a continuous description was fitted based on the GAB theoretical modelling. The numerical identification of fitting parameters used a non-linear least-squares minimization procedure based on Levenberg-Marquardt algorithm (Marquardt, 1963). The main advantage of this method is that, besides the determination of best-fit parameters, it provides an estimation of the standard deviation associated with each parameter. This allows to take into account the accuracy of the experimental procedure and above all the variability between samples. Therefore, it is possible to evaluate a standard deviation associated with each value of the theoretical fitting, and in particular with the various critical water content defined later in the Discussion.

Concerning the 5 limestones under investigation, sorption isotherm curves are plotted in Fig. 2. It shows a classical pattern with a significant increase in water content above $90 \% R H$. This upper $R H$ range corresponds to the setting up of capillary interfaces where the liquid phase starts to be considered as "free" water. The 5 limestones exhibit different behaviours since Estaillades samples (ES) are weakly hygroscopic while sorption capacities in 


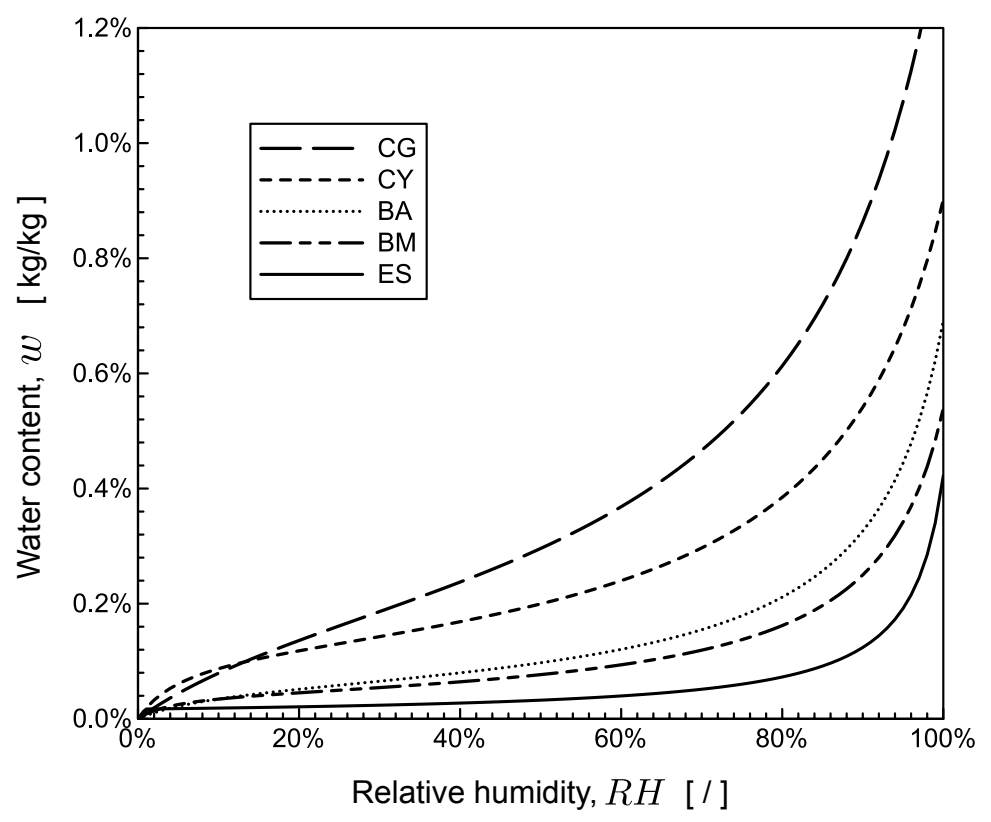

Figure 2: Sorption isotherm curves of the 5 limestones.

grey Caromb ones $(\mathrm{CG})$ is much more important.

\subsection{Mechanical strengths}

The tensile strength was determined indirectly by means of the "Brazilian" test. It consists in imposing a diametrical compressive stress on cylindrical samples (40 mm diameter $\times 40 \mathrm{~mm}$ length) which generates tensile stress perpendicular to the loading direction. The contact between sample and testing machine is done with a piece of cardboard to ensure a better load distribution and avoid stress concentration. Constant loading velocity of $5 \times 10^{-6} \mathrm{~m} \cdot \mathrm{s}^{-1}$ is imposed to have a sample failure about 15 minutes after the beginning of the test.

The compressive strength was measured directly on drilling core samples (40 mm diameter $\times 80 \mathrm{~mm}$ length) with coplanar end-faces. The contact between sample and testing machine is done with 2 sheets of Teflon ( $1 \mathrm{~mm}$ thick) to have perfect sliding conditions at both end-faces and ensure a uniform compressive stress state inside the sample. Constant loading velocity of $1 \times 10^{-5} \mathrm{~m} . \mathrm{s}^{-1}$ is imposed to have a sample failure about 15 minutes after the beginning of the test.

For both tests, samples were drilled perpendicularly to the bedding. Since the framework of this study concerns the spalling phenomenon, the objective was to have in all cases a crack plane that develops perpendicularly to the bedding. After geometrical preparation, all specimens were dried at $65^{\circ} \mathrm{C}$ until weight constancy was achieved. To measure mechanical properties as functions of water content, samples were divided in 5 groups to cover the whole range of water content: 
- the $1^{\text {st }}$ group was characterized directly in the dry state,

- the $2^{\text {nd }}$ group was equilibrated in a $75 \% \mathrm{RH}$ atmosphere using a $\mathrm{NaCl}$ saturated solution,

- the $3^{\text {rd }}$ group was equilibrated in a $97 \% \mathrm{RH}$ atmosphere using a $\mathrm{K}_{2} \mathrm{SO}_{4}$ saturated solution,

- the $4^{\text {th }}$ group was saturated with water under vacuum conditions,

- the $5^{\text {th }}$ group was saturated with water under vacuum conditions, then dried in a $44 \%$ $\mathrm{RH}$ atmosphere using a $\mathrm{K}_{2} \mathrm{CO}_{3}$ saturated solution until the required water content was reached.

To characterize the hydric state of samples, the mass water content is defined by the mass ratio between liquid and solid phases:

$$
w=\frac{m_{w}}{m_{s}}
$$

For each limestone, the compressive and tensile strengths are plotted as functions of the water content in Figs. 3 to 7 . As already evidenced, the ultimate strengths of sedimentary rocks highly depend on the water content. It usually shows a strong decrease for low water content and almost constant values for larger water content. To describe this behaviour, Hawkins and McConnell (1992) and Vásárhelyi and Ván (2006) have proposed a simple representation written as:

$$
\sigma(w)=a e^{-b w}+c
$$

introducing 3 material parameters $(a, b$ and $c$ ). As described in previous section, the numerical identification used a non-linear least-squares minimization procedure that provides not only the best-fit parameters, but also an estimation of the standard deviation associated with each parameter. The values obtained from experimental measures are given in Tab. 3 while corresponding representations are plotted as dotted lines in Figs. 3 to 7.

Even if $3^{\text {rd }}$ and $4^{\text {th }}$ groups of samples are prepared from different initial states, i.e., the $3^{\text {rd }}$ group is wetted from a dry state while the $4^{\text {th }}$ group is dried from a saturated state, the mechanical strengths obtained for both groups are relatively close. This supports the idea that the water content is the appropriate variable to describe the weakening phenomenon. Furthermore, it underlines the reversibility of weakening process since the evolution of mechanical strength as a function of water content can be characterized both ways.

\section{Discussion}

Dry and saturated mechanical strengths have been reported for various rocks and stones while the complete evolution over the whole range of water content has been less frequently 


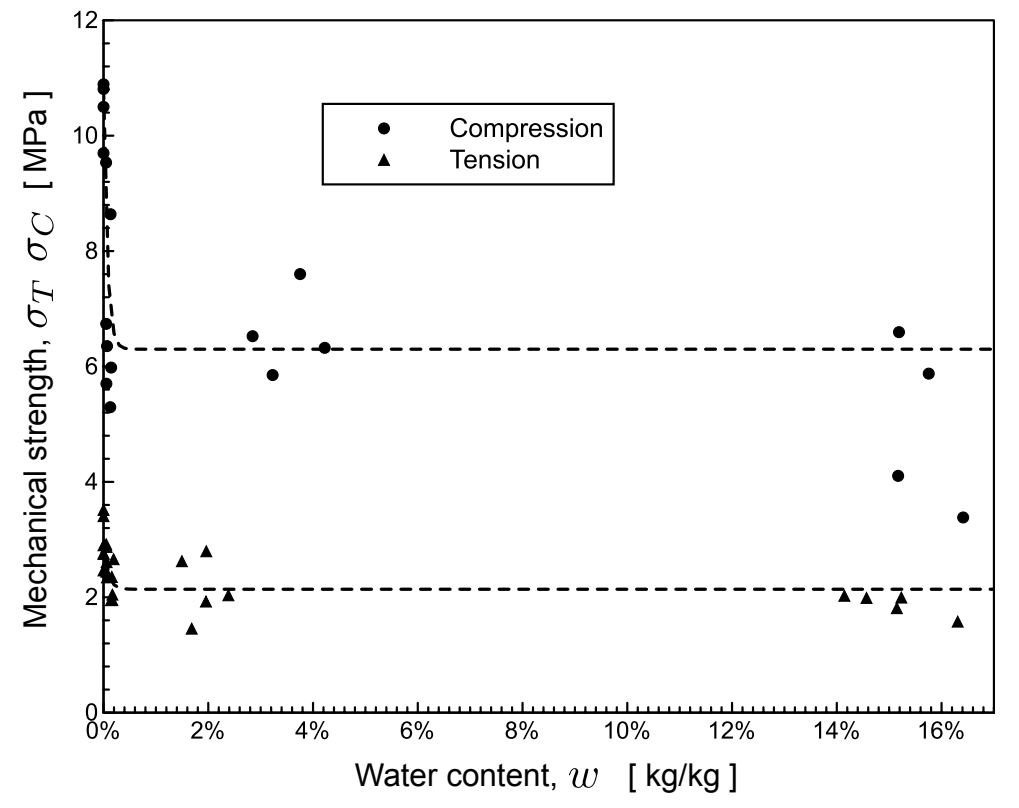

Figure 3: Mechanical strengths of Estaillades (ES) limestone in tension and compression as functions of water content.

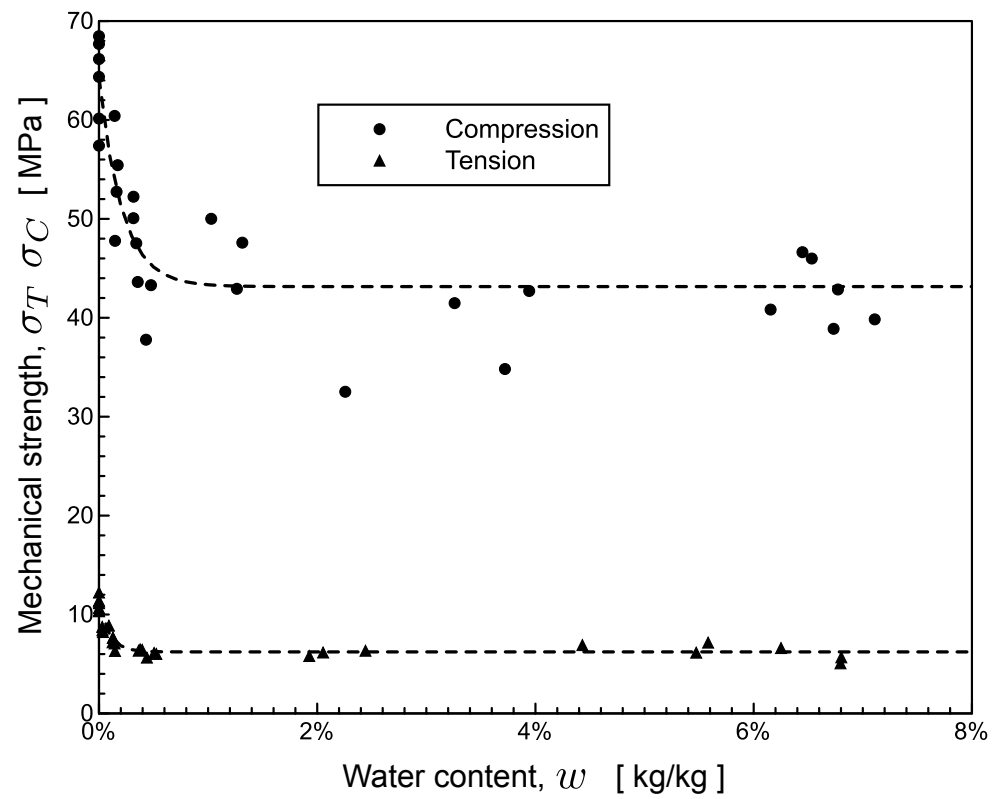

Figure 4: Mechanical strengths of modern Barutel (BM) limestone in tension and compression as functions of water content. 


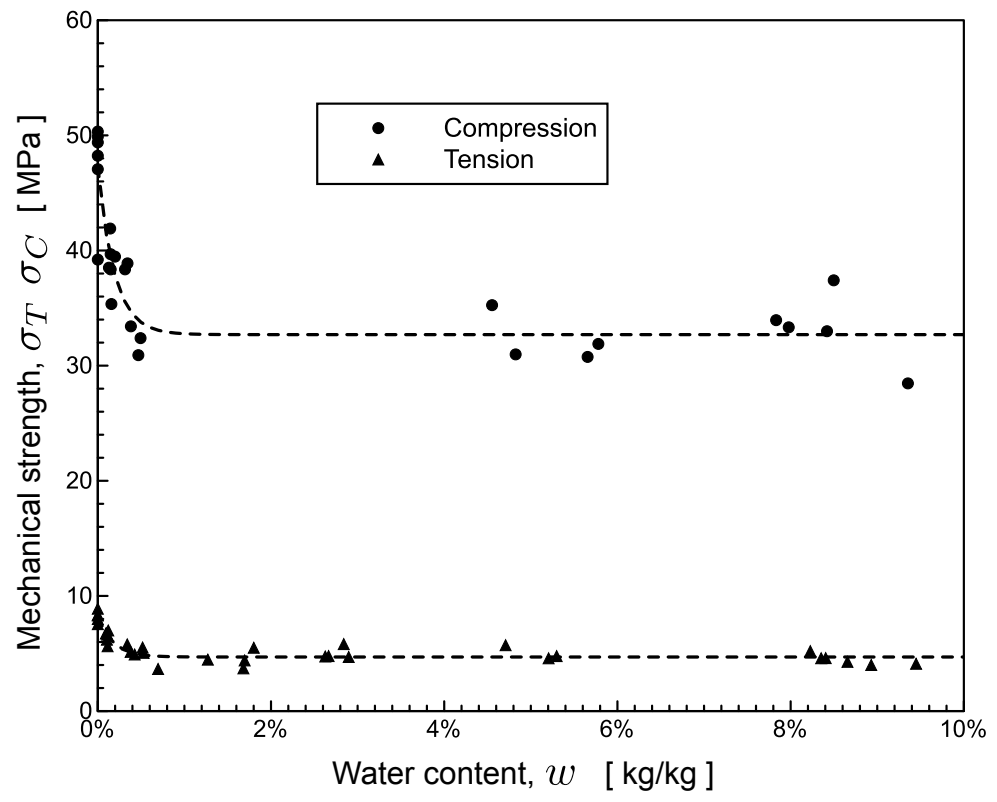

Figure 5: Mechanical strengths of antique Barutel (BA) limestone in tension and compression as functions of water content.

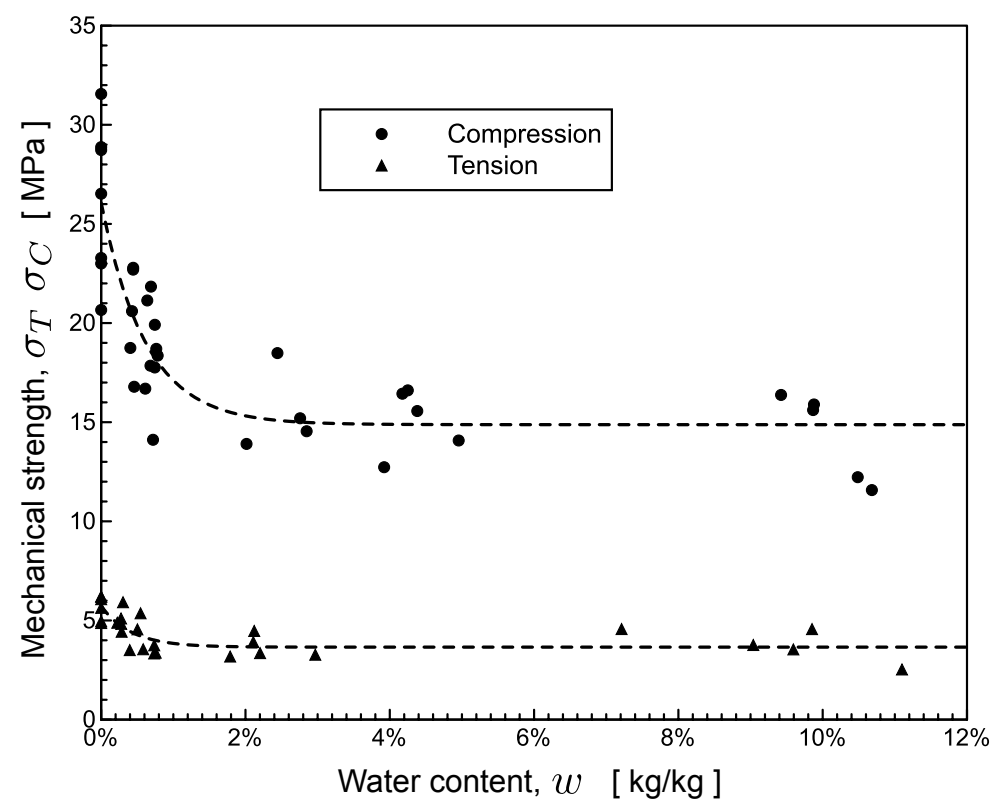

Figure 6: Mechanical strengths of yellow Caromb (CY) limestone in tension and compression as functions of water content. 


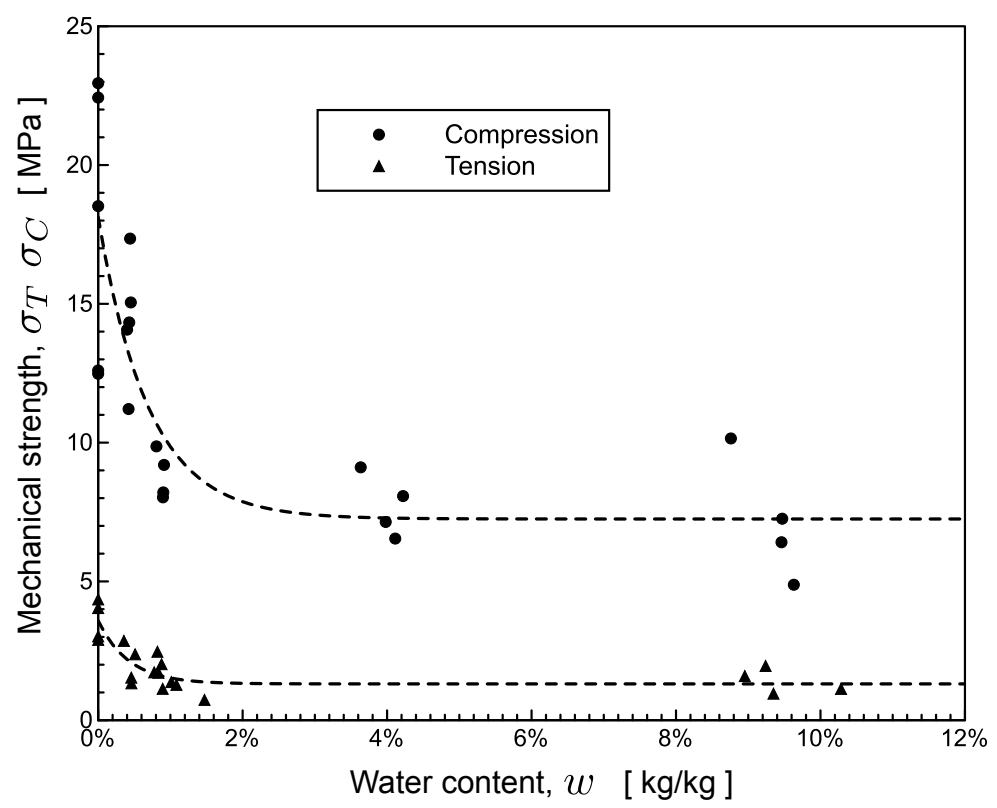

Figure 7: Mechanical strengths of grey Caromb (CG) limestone in tension and compression as functions of water content.

Table 3: Values of material parameters introduced to describe the tensile and compressive strengths as functions of water content (Eq. 2)

\begin{tabular}{rccccc}
\hline & ES & BM & BA & CY & CG \\
\hline Tensile strength $\sigma_{T}$ & & & & & \\
$a_{T}$ & $0.850 \pm 0.175$ & $4.69 \pm 0.278$ & $3.47 \pm 0.268$ & $2.06 \pm 0.339$ & $2.27 \pm 0.354$ \\
$b_{T}$ & $1190 \pm 635$ & $1010 \pm 236$ & $564 \pm 120$ & $240 \pm 92$ & $237 \pm 90$ \\
$c_{T}$ & $2.14 \pm 0.116$ & $6.22 \pm 0.165$ & $4.70 \pm 0.128$ & $3.66 \pm 0.217$ & $1.31 \pm 0.240$ \\
Compressive strength $\sigma_{C}$ & & & & & \\
$a_{C}$ & $4.50 \pm 0.943$ & $21.1 \pm 2.04$ & $14.6 \pm 1.50$ & $11.2 \pm 1.17$ & $10.9 \pm 1.63$ \\
$b_{C}$ & $1400 \pm 753$ & $473 \pm 115$ & $523 \pm 132$ & $161 \pm 36.8$ & $143 \pm 49.5$ \\
$c_{C}$ & $6.30 \pm 0.609$ & $43.2 \pm 1.24$ & $32.7 \pm 0.95$ & $14.9 \pm 0.71$ & $7.25 \pm 1.05$ \\
\hline
\end{tabular}


characterized (Ojo and Brook, 1990; West, 1994; Hawkins and McConnell, 1992; Papamichos et al, 1997; Talesnick et al, 2001; Grgic et al, 2005; Vásárhelyi and Ván, 2006; MoralesDemarco et al, 2007; Erguler and Ulusay, 2009; Yilmaz, 2010). Intensive research focused on the understanding of the effect of water on the loss of mechanical strength. It aimed at establishing some correlations between dry and saturated mechanical properties with respect to various petrophysical characteristics, porosity (Morales-Demarco et al, 2007; Vasconcelos et al, 2008; Török and Vásárhelyi, 2010), density (Vásárhelyi, 2005; Morales-Demarco et al, 2007; Török and Vásárhelyi, 2010) or mineral composition (Yilmaz et al, 2011). Actually, it corresponds to the analysis of $a$ and $c$ parameters given in Eq. 2 and Tab. 3. However, fewer studies have been carried out to understand the variation of mechanical properties as a function of water content, which is associated with parameter $b$. Its influence could be synthesized as: the larger the $b$-parameter, the lower the water content at which the mechanical strengths are equal to their saturated values. By merging various experimental data, Vásárhelyi and Ván (2006) underlined an inverse correlation between the $b$-parameter and the porosity. With a slightly different description, a similar tendency has been highlighted by Erguler and Ulusay (2009).

To identify some correlation between results, several critical water contents can be defined. The $1^{s t}$ one, $w_{S}$, is associated with the sorption isotherm curves and corresponds to the water content observed at $97 \% R H$, which is written:

$$
w_{S}=w(R H=0.97)
$$

This critical water content can be seen as the upper limit of the hygroscopic domain. It has already been shown that the clayey fraction plays a significant role in the sorption behaviour and more specifically the smectite layers. To evidence their influence on the sorption behaviour, the sorption critical water content, $w_{S}$, is plotted as a function of the smectite content in Fig. 8. An affine dependence is obtained highlighting the direct influence of the clay fraction on sorption characteristics. Obviously, the clay fraction is not the only parameter that governs the sorption behaviour. It also highly depends on the micro-structure and specifically on the pore size distribution. Barutel limestones are fine-grained calcite that can be described as micrite. Apart from clay, its large micro-porosity accounts for its hygroscopicity even if its smectite content is relatively low. On the contrary, Caromb limestones are composed of large fragments $(>500 \mu \mathrm{m})$ cemented by a sparse and unevenly distributed calcareous matrix. Its lower micro-porosity gives a predominant significance to the clay fraction.

The $2^{\text {nd }}$ and $3^{\text {rd }}$ critical water contents, $w_{T}$ and $w_{C}$, are associated with tensile and compressive properties and correspond to the water contents at which the drop in tensile or compressive strength is equal to $90 \%$ of the total drop between dry and saturated values. From Eq. 2, they are defined as:

$$
w_{T}=-\ln (0.10) / b_{T} \quad w_{C}=-\ln (0.10) / b_{C}
$$




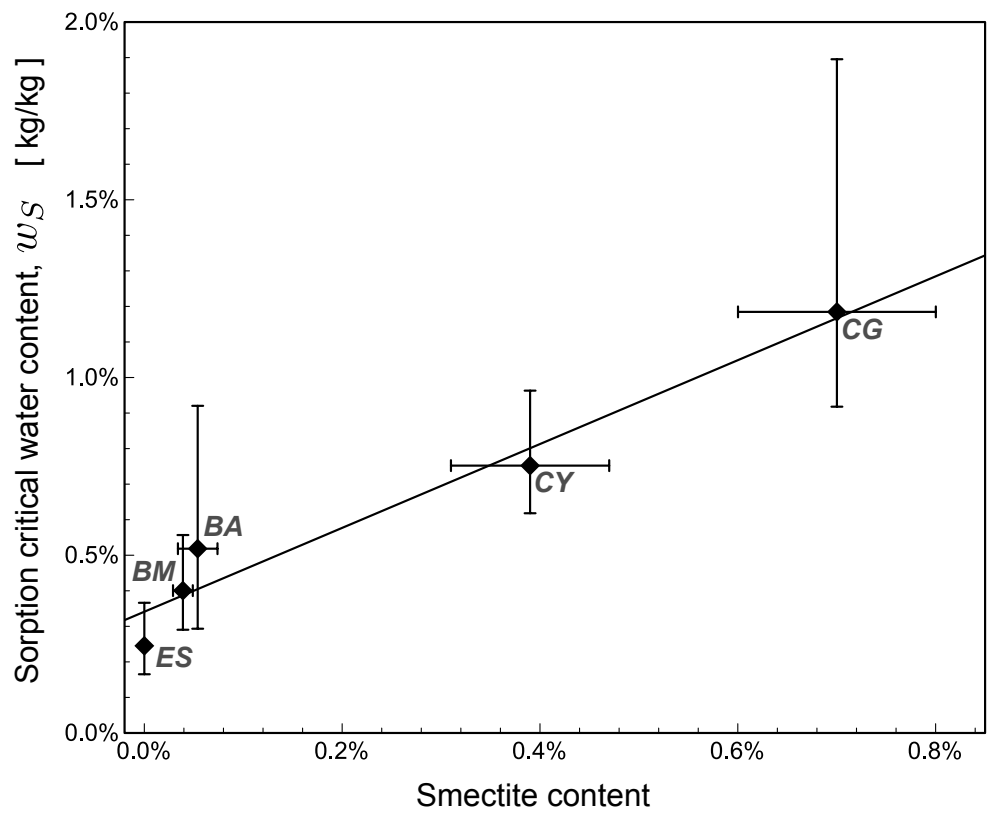

Figure 8: Sorption critical water content, $w_{S}$, as a function of the smectite content.

One can note that these latter water contents only depend on the $b$-parameter allowing discussing the sole influence of this dimensionless property.

The tensile and compressive critical water contents, $w_{T}$ and $w_{C}$, are plotted as functions of the sorption critical water content, $w_{S}$, in Figs. 9 and 10. The bisector lines are given for indication. These dependences are fairly described by linear relationships, i.e., the range of water content in which the mechanical properties depend on moisture corresponds roughly to the hygroscopic domain. This means that, for the 5 limestones under investigation, the loss of mechanical strengths is almost maximal at $97 \% R H$. Therefore, it is not necessary to subject these limestones to rain or flooding to observe the softening behaviour, a $97 \% R H$ atmosphere is sufficient to get a substantial loss of mechanical properties. This issue is of major importance in building and civil engineering since all material is affected by softening and not only the external parts subjected to rain or the lower parts where capillary rise occurs.

Therefore, the clay content has a direct impact on the dependence of mechanical characteristics with respect to water content. The larger the clay content, the wider the hygroscopic domain and consequently, the higher the water content above which the mechanical strengths are constant and equal to their value at saturation. From these observations, the determination of the complete dependence on water content requires the measure of the mechanical characteristics in 3 moisture conditions: dry, saturated and equilibrated with a $97 \% R H$ atmosphere. This is sufficient to estimate the 3 parameters introduced in Eq. 2.

Eventually, a softening/weakening coefficient can be calculated by:

$$
S=\frac{\sigma^{d r y}-\sigma^{s a t}}{\sigma^{d r y}}
$$




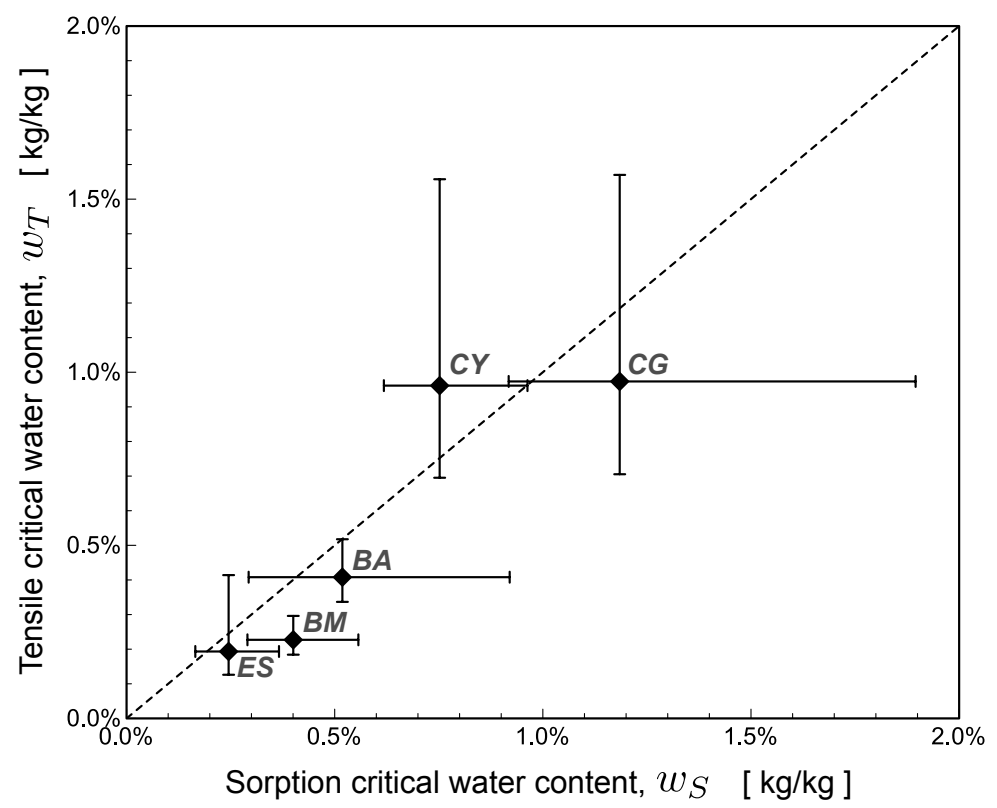

Figure 9: Tensile critical water content, $w_{T}$, as a function of the sorption critical water content, $w_{S}$.

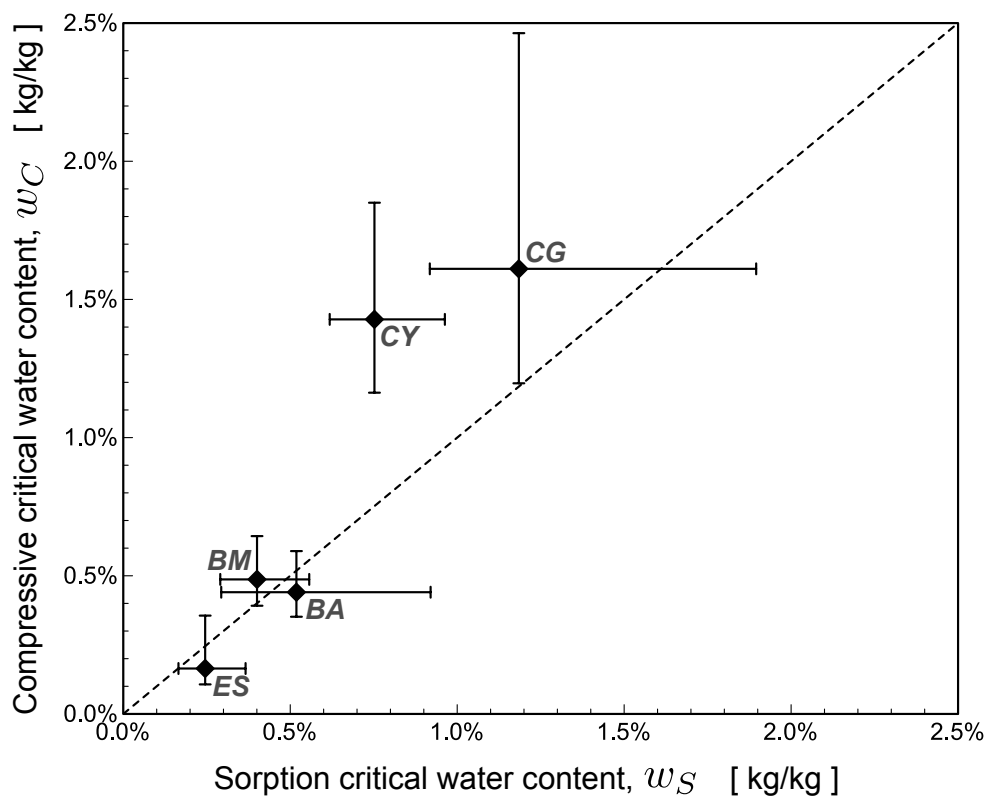

Figure 10: Compressive critical water content, $w_{C}$, as a function of the sorption critical water content, $w_{S}$. 
In tension and compression, softening coefficients are plotted as functions of the smectite content in Fig. 11. Previous works intended to highlight some dependences of softening phenomenon on porosity (Vasconcelos et al, 2008) or clay content (Hawkins and McConnell, 1992; Benavente et al, 2008). However, such correlations cannot be underlined in our experimental results. While the role of clay content in the rate of strength loss has clearly been evidenced, it seems to have no influence on the intensity of this strength loss.

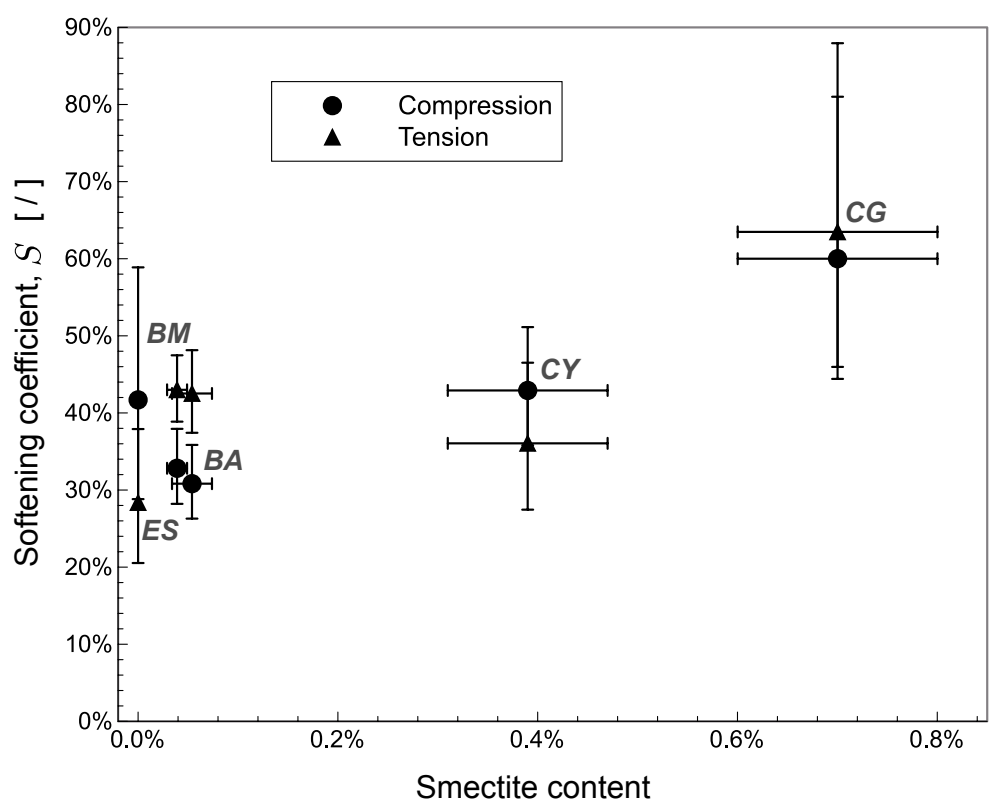

Figure 11: Tensile and compressive softening coefficients as functions of the smectite content.

So far, the mechanisms whereby the mechanical strength decreases with the water content are not clearly established. Several processes have been put forth in the literature such as fracture energy reduction, capillary tension decrease, pore pressure increase, frictional reduction, or chemical and corrosive deterioration. Furthermore, the hydric dilation behaviour might be an additional factor influencing the mechanical strength.

The decreasing suction as water content increases has widely been supposed to account for the material weakening induced by wetting (West, 1994; Papamichos et al, 1997; Grgic et al, 2005). Nevertheless, grain scale experiments have recently evidenced that capillary forces vanish with the drying of the meniscus (Mielniczuk et al, 2014a,b). Even if this mechanism effectively occurs, it would represent a minor contribution to the weakening phenomenon (Ciantia et al, 2015a).

Recently, Ciantia and Hueckel (2013); Ciantia et al (2015a,b) have highlighted another mechanism that takes place in calcareous rocks. By coupling SEM, X-ray CT observations and macroscopic experiments, they identified two distinct types of bonding between calcite grains. On one hand, temporary bonds of depositional origin can fall into suspension while wetting and redeposit during drying. These bonds are associated with a short-term and 
reversible weakening that affects instantly the rock as water content varies. On the other hand, persistent calcite bonds of diagenetic origin give the material its solid structure. When exposed to a slow process of dissolution, it leads to a long-term and irreversible weakening.

Even if the five limestones under investigation exhibit significant differences in their microstructure when compared to the calcareous rock analysed in their work, the ideas pointed out are attractive. From our view, the weakening process investigated in this work could be associated with temporary bonds of depositional origin since it is a short-term and reversible phenomenon. Thus, the clay fraction plays the role of a retardation factor which tends to shift the softening process towards larger water content. Indeed, given the high hygroscopicity of smectite, the appearance of capillary bridges and free water occur at larger water content (Fig. 2) and may delay the re-suspension of temporary bonds. This hypothesis is supported by the linear correlation underlined in Figs. 9 and 10. However, the amount of clay minerals does not influence the intensity of weakening that would depend on the ratio between depositional and diagenetic bonds.

\section{Conclusions}

The mechanical weakening of sedimentary stones induced by wetting is a well-known and extensively characterized phenomenon. However, the physical processes governing this loss in strength have not been clearly identified and quantified. Considering that clay minerals play a major role in the hydro-mechanical behaviour of limestones, their influence on weakening process is worth being investigated.

In order to sense the internal factors involved in such decay mechanisms, experimental characterization has been carried out. Precise clay mineral quantification was performed thanks to a methodology developed recently coupling transmission electron microscopy, Xray spectrometry, X-ray diffraction and numerical modelling. Sorption isotherm curves were characterized using standard saturated salt solutions. Then, tensile and compressive mechanical strengths were determined as functions of the water content. By correlating these results, it is clear that the clay minerals content directly influences the sorption capacity which in turn, governs the rate of strength loss. Regarding the five limestones under investigation, it is evidenced that $90 \%$ of the strength loss is observed when samples are equilibrated with a $97 \%$ RH atmosphere. Indeed, the weakening is almost complete in a vapour saturated environment. With engineering purposes, this sorption critical water content $w_{S}$ has a particular meaning with respect to the hydro-mechanical behaviour since it defines, on one hand, the upper limit of the hygroscopic domain and, on the other hand, a change in the dependences of mechanical properties on the water content. A complete characterization of mechanical strengths could be built on the measurements in 3 moisture conditions: dry, saturated and equilibrated with a $97 \% R H$ atmosphere.

Since water has a similar effect on various geo-materials, the observations put forth in 
this work can have a larger impact. In particular, the micro-scale mechanisms highlighted by Ciantia et al $(2015 \mathrm{a}, \mathrm{b})$ on calcareous rock may govern the mechanical weakening in the case of other carbonates. From their high water storage capacity, it suggests that the clay minerals "delay" the appearance of capillary bridges and free water. Thus, the re-suspension of depositional bonds at the origin of weakening is shifted towards larger water content.

\section{Acknowledgements}

This work was done within the framework of a collaboration between the CICRP and the LMGC supported by the French Ministry of Culture and Communication through the PNRCC program (Programme National de Recherche sur la Connaissance et la Conservation du patrimoine culturel matériel).

\section{References}

Benavente D, Cultrone G, Gómez-Hera M (2008) The combined influence of mineralogical, hygric and thermal properties on the durability of porous building stones. European Journal of Mineralogy 20:673-685, DOI 10.1127/0935-1221/2008/0020-1850

Berthonneau J, Grauby O, Ferrage E, Vallet JM, Bromblet P, Dessandier D, Chaudanson D, Baronnet A (2014) Impact of swelling clays on the spalling decay of building limestones: Insights from x-ray diffraction profile modeling. European Journal of Mineralogy 26:643656

Berthonneau J, Bromblet P, Cherblanc F, Ferrage E, Vallet JM, Grauby O (2015) The spalling decay of building bioclastic limestones of provence (south east of france): from clay minerals swelling to hydric dilation. Journal of Cultural Heritage

Ciantia MO, Hueckel T (2013) Weathering of submerged stressed calcarenites: chemomechanical coupling mechanisms. Géotechnique 63:768-785, DOI 10.1680/geot.SIP13.P.024

Ciantia MO, Castellanza R, Crosta G, Hueckel T (2015a) Effects of mineral suspension and dissolution on strength and compressibility of soft carbonate rocks. Engineering Geology 184:1-18, DOI 10.1016/j.enggeo.2014.10.024

Ciantia MO, Castellanza R, di Prisco C (2015b) Experimental study on the water-induced weakening of calcarenites. Rock Mechanics and Rock Engineering 48:441-461, DOI $10.1007 / \mathrm{s} 00603-014-0603-\mathrm{Z}$

Colas E, Mertz JD, Thomachot-Schneider C, Barbin V, Rassineux F (2011) Influence of the clay coating properties on the dilation behavior of sandstones. Applied Clay Science $52: 245-252$ 
Drits VA, Tchoubar C (1990) X-ray diffraction by disordered lamellar structures: theory and applications to microdivised silicates and carbons. Springer-Verlag

Erguler ZA, Ulusay R (2009) Water-induced variations in mechanical properties of claybearing rocks. International Journal of Rock Mechanics \& Mining Sciences 46:355-370, DOI 10.1016/j.ijrmms.2008.07.002

Ferrage E, Vidal O, Mosser-Ruck R, Cathelineau M, Cuadros J (2011) A reinvestigation of smectite illitization in experimental hydrothermal conditions: Results from x-ray diffraction and transmission electron microscopy. American Mineralogist 96:207-223

Franzini M, Leoni L, Lezzerini M, Cardelli R (2007) Relationships between mineralogical composition, water absorption and hydric dilatation in the macigno sandstones from lunigiana (massa, tuscany). European Journal of Mineralogy 19:113-123

Grgic D, Giot R, Homand F, Giraud A (2005) Effect of suction on the mechanical behaviour of iron ore rock. International Journal for Numerical and Analytical Methods in Geomechanics 29:789-827, DOI 10.1002/nag.438

Hawkins AB, McConnell BJ (1992) Sensitivity of sandstone strength and deformability to changes in moisture content. Quaterly Journal of Engineering Geology 25:115-130

Howard S, Preston K (1989) Profile fitting of powder diffraction patterns. Reviews in Mineralogy and Geochemistry 20:217-275

Jiménez-González I, Rodríguez-Navarro C, Scherer G (2008) Role of clay minerals in the physicomechanical deterioration of sandstone. Journal of Geophysical Research 113:F02,021, DOI 10.1029/2007JF000845

Lanson B, Sakharov BA, Claret F, Drits VA (2009) Diagenetic smectite-to-illite transition in clay-rich sediments: a reappraisal of x-ray diffraction results using the multi-specimen method. American Journal of Science 309:476-516

Marquardt DW (1963) An algorithm for least-squares estimation of nonlinear parameters. Journal of the Society for Industrial and Applied Mathematics 11:431-441

Mielniczuk B, Hueckel T, Youssoufi MSE (2014a) Evaporation-induced evolution of the capillary force between two grains. Granular Matter 16(5):815-828, DOI 10.1007/s10035-0140512-6

Mielniczuk B, Hueckel T, Youssoufi MSE (2014b) Rupture of a liquid bridge between two grains due to its evaporation. Acta Geophysica 62(5):1087-1108, DOI 10.2478/s11600-0140225-6 
Morales-Demarco M, Jahns E, Ruedrich J, Oyhantcabal P, Siegesmund S (2007) The impact of partial water saturation on rock strength: an experimental study on sandstone. Z dt Ges Geowiss 158:869-882, DOI 10.1127/1860-1804/2007/0158-0869

Ojo O, Brook N (1990) The effect of moisture on some mechanical properties of rock. Mining Science and Technology 10:145-156

Papamichos E, Brignoli M, Santarelli F (1997) An experimental and theoretical study of a partially saturated collapsible rock. Mechanics of Cohesive-Frictional Materials 2:251-278

Revil A, Lu N (2013) Unified water isotherms for clayey porous materials. Water Resources Research 49:56855699, DOI 10.1002/wrcr.20426

Ruedrich J, Bartelsen T, Dohrmann R, Siegesmund S (2011) Moisture expansion as a deterioration factor for sandstone used in buildings. Environmental Earth Science 63:1545-1564, DOI $10.1007 / \mathrm{s} 12665-010-0767-0$

Sebastián E, Cultrone G, Benavente D, Fernandez LL, Elert K, Rodríguez-Navarro C (2008) Swelling damage in clay-rich sandstone used in the church of san mateo in tarifa (spain). Journal of Cultural Heritage 9:66-76, DOI 10.1016/j.culher.2007.09.002

Talesnick M, Shehadeh S (2007) The effect of water content on the mechanical response of a high-porosity chalk. International Journal of Rock Mechanics \& Mining Sciences 44:584600, DOI 10.1016/j.ijrmms.2006.07.016

Talesnick ML, Hatzor YH, Tsesarsky M (2001) The elastic deformability and strength of a high porosity, anisotropic chalk. International Journal of Rock Mechanics \& Mining Sciences $38: 543-555$

Török A, Vásárhelyi B (2010) The influence of fabric and water content on selected rock mechanical parameters of travertine, examples from hungary. Engineering Geology 115:237245, DOI 10.1016/j.enggeo.2010.01.005

Vásárhelyi B (2005) Statistical analysis of the influence of water content on the strength of the miocene limestone. Rock Mechanics and Rock Engineering 38:69-76, DOI 10.1007/s00603004-0034-3

Vásárhelyi B, Ván P (2006) Influence of water content on the strength of rock. Engineering Geology 84:70-74, DOI 10.1016/j.enggeo.2005.11.011

Vasconcelos G, Lourenço PB, Alves CAS, Pamplona J (2008) Ultrasonic evaluation of the physical and mechanical properties of granites. Ultrasonics 48:453-466, DOI 10.1016/j.ultras.2008.03.008 
Vergès-Belmin V (ed) (2008) Illustrated glossary on stone deterioration patterns. ICOMOS, International Scientific Committee for Monuments and Sites (www.icomos.org)

Weiss T, Siegesmund S, Kirchner D, Sippel J (2004) Insolation weathering and hygric dilatation: two competitive factors in stone degradation. Environmental Geology 46:402-413, DOI 10.1007/s00254-004-1041-0

West G (1994) Effect of suction on the strength of rock. Quaterly Journal of Engineering Geology 27:51-56

Woodruff WF, Revil A (2011) Cec-normalized clay-water sorption isotherm. Water Resources Research 47:W11,502, DOI 10.1029/2011WR010919

Yilmaz I (2010) Influence of water content on the strength and deformability of gypsum. International Journal of Rock Mechanics \& Mining Sciences 47:342-347, DOI 10.1016/j.ijrmms.2009.09.002

Yilmaz NG, Goktan RM, Kibici Y (2011) Relations between some quantitative petrographic characteristics and mechanical strength properties of granitic building stones. International Journal of Rock Mechanics \& Mining Sciences 48:506-513, DOI 10.1016/j.ijrmms.2010.09.003 